\title{
Polymicrogyria of the Unilateral Temporal Lobe in a Transsexual Patient-Case Report
}

\author{
Ana Starcevic $^{1}$, Dusica Markovic Zigic ${ }^{2}$, Branislav Filipovic ${ }^{1}$ \\ ${ }^{1}$ Institute of Anatomy “Niko Miljanic”, Faculty of Medicine, University of Belgrade, Belgrade, Serbia; ${ }^{2}$ Psychiatry Hospital, Clinical \\ Center Dedinje “Dr Dragisa Misovic”, Belgrade, Serbia. \\ Email: ana.starcevic79@yahoo.com
}

Received April 19 ${ }^{\text {th }}, 2013$; revised May $18^{\text {th }}, 2013$; accepted June $14^{\text {th }}, 2013$

Copyright (c) 2013 Ana Starcevic et al. This is an open access article distributed under the Creative Commons Attribution License, which permits unrestricted use, distribution, and reproduction in any medium, provided the original work is properly cited.

\begin{abstract}
Introduction: Polymicrogyria, the appearance of irregular small and over numbered gyri on the surface of the brain, has been reported as the most frequent finding, when exists, on the temporal lobe. Case Presentation: A patient, male, age of 35, came to the regular head and brain MRI scan due to psychiatric and hormonal treatment within transsexualism. There were no data of epilepsy in a patient's history. MRI scans were acquired with a $1.5 \mathrm{~T}$ Siemens Magnetom system with a standard head coil. Three-dimensional 3D RAGE, contiguous $1.0 \mathrm{~mm}$ slice, and 1 acquisition sequence underwent final 3D rendering and subsequent volumetry. On the definitive 3D image, we have revealed an unusual gyrisation on the left temporal lobe which had a picture of partial polymicrogyria. Conclusion: This is a unique finding, to our knowledge, of the unilateral temporal polymicrogyria in a person with transsexualism. Although polymicrogyria is mostly related to epileptifom attacks, its impact on the transsexualism appearance is opened to be examined.
\end{abstract}

Keywords: Transsexualism; Polymicrogyria; MRI

\section{Introduction}

Transsexuality is characterized by a strong conviction of having been born in the wrong body and is also considered to be the extreme end of the spectrum of gender identity disorders characterized by a pursuit of sex reassignment surgery [1]. Transsexuals experience themselves as being of the opposite sex, despite having the biological characteristics of one sex. There can be seen a strong psychological rejection of the actual body. Female-to-male transsexuals and male-to-female transsexuals are characterized by persistent male or female identification and constant feeling of being trapped in the wrong body, which is seems to be their permanent kind of a obsessive thought and final life goal as gender identification is the basic human psychological characteristics.

There might be many factors that can influence the development of this disorder and it has been implicated that genetic, hormonal and psychological factors are the most dominant. There is also a fact that there must be a morphological substrate like in every disorder that serves like a base or material for development of the disorder.
Polymicrogyria is one of the most common malformations of cortical development. It is often associated with specific syndromes, and has a wide variety of clinical presentation [2-4]. It is considered to be a cortical malformation development in which normal process of cortical development is somehow stopped by different factors. Some of them are defined in the late stage of neuronal migration or in the early stage of neuronal organisation [4,5]. Polymicrogyria is a malformation with many faces, so it is of major significance to have that in mind when examing the MRI scans. It is mostly related to epileptic attacks, and its impact on the transsexualism appearance is opened to be examined.

\section{Case Presentation}

Our patient is male to female transsexual, thirty five years of age. He was reported to Counsiling Service for Sexual and Gender Identity Disorder. During the interview, he gave data on feeling different since childhood as a female trapped in a male body. He mentioned he liked to play more with his girlfriends and felt like he is one of them. It was at the age of four. His mother thought it was 
a transit stage of childhood.

The patient went through regular psychological and neurological examination. His psychical and neurological status showed no symptoms and no signs of epilepsy or any other associated disease. He is left handed and has no data of drug history. This is an unoperated patient, untreated by hormone therapy. He is currently undergoing real life test under occasional psychiatric supervision and support. He has two children from two marriages, eight years old son and three months old daughter. The patient is bacheleor in electric sciences, working two jobs which are not in his field of professional interest.

There were some problems during his first marriage. He had difficulties in expressing his true feeling. A chance to express his true feeling was given in the present marriage. Nevertheless, he is still submitted to occasional psychological torture by his ex wife who considers him as a monster. On the other hand he found very big support in his present wife who accepted his condition.

In the course of diagnostic and scientific evaluation, MRI brain scan was performed. During the procedure an unusual gyrisation of the left temporal lobe was revealed. That was considered to be partial polymicrogyria.

MRI exams were performed on SIEMENS AVANTO TIM 1.5 T (SIEMENS, Erlangen, Germany) using 3DFLAIR $(\mathrm{TR} / \mathrm{TI} / \mathrm{TE}=6000 / 2200 / 300 \mathrm{~ms})$ and MPRAGE $(\mathrm{TR} / \mathrm{TE}=2000 / 5 \mathrm{~ms})$ sequences.

Slice thickness in former case was $1 \mathrm{~mm}$ (no gap), while in latter cases images with same thickness were obtained with post-reconstruction from $1 \mathrm{~mm}$ sagittal MR scans. After completion of examination, MR images were transferred to personal computer and processed using MIPAV software package (National Institute of
Health, Bethesda, USA). Separation of brain tissue from surrounding structures on sagittal 3DFLAIR and MPRAGE images and brain volume estimation was performed using Brain extraction tool (BET). Rendering procedure was used to generate 3D view of brain surface. Estimation (i.e. segmentation) of gray and white matter volumes was performed using fuzzy means algorithm implemented in MIPAV.

We noted peculiar shape of the Sylvian fissure on the polymicrogyric hemisphere with the absence of ascending branch (Figure 1). The posterior branch is interrupted and terminates at the level of the preoccipital notch (Figure 2). The cause of interruption is polymicrogyria in the parietotemporal region (Figure 3).

Brain segmentation showed difference in white matter volume but not in grey volume. There were no differences in estimated brain volume.

\section{Discussion}

Although public awareness is dramatically increased in past few decades, our scientific understanding and explanation of gender identity disorder is still very poor and pretty limited. The factors can be different, but we can determine on genetic, endocrine or hormonal or psychosocial [6-8].

There is an impressive data gathered predominantly from laboratory animals, of the influence of gonadal steroid hormones on the prenatal or perinatal sexual differentiation of the brain. Studies in humans have shown that levels of circulating sex steroids and estrogen feedback on luteinizing hormone do not differ between transsexuals and controls [9-11]. Testicular hormones also play very important role in the sexual differentiation
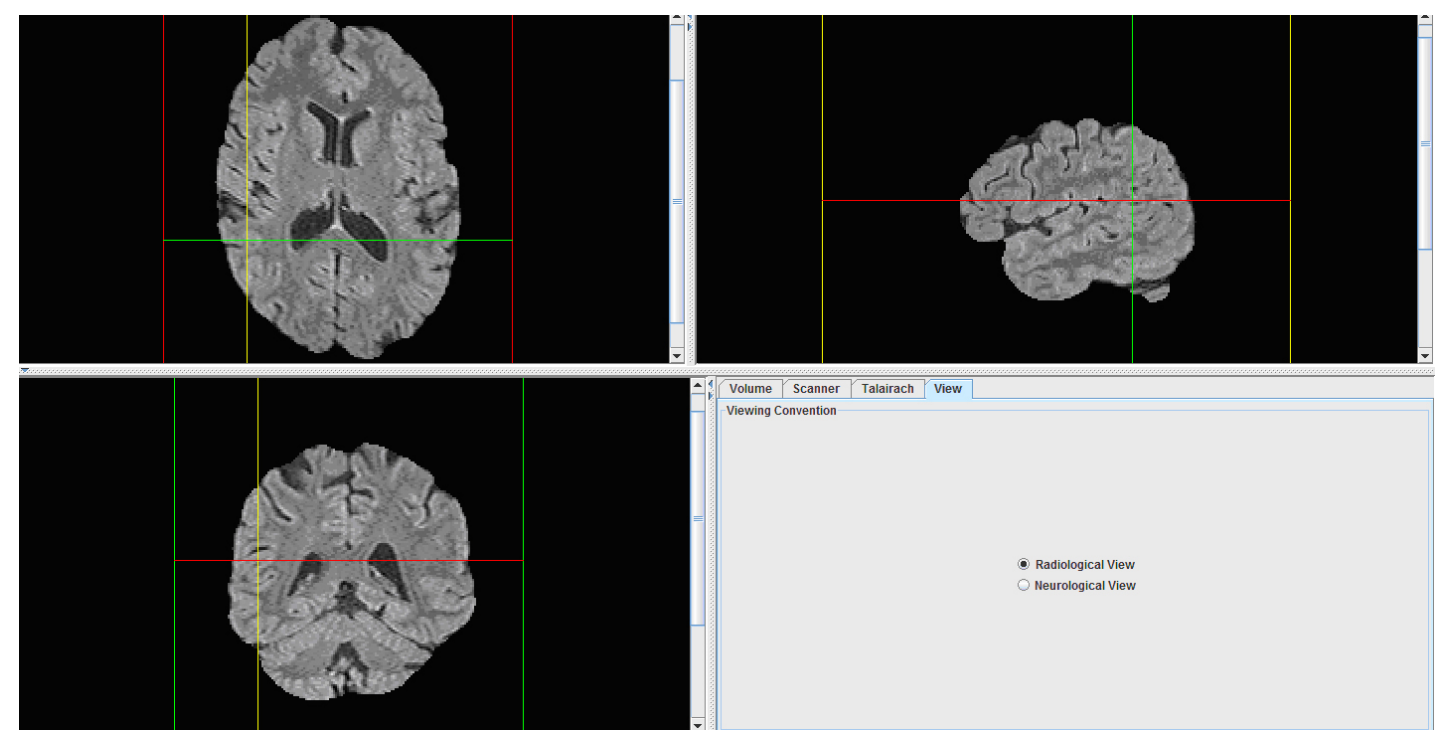

Figure 1. Three different MRI aspect show specific region of parieto-temporal lobe with a peculiar shape of the Sylvian fissure on the polymicrogyric hemisphere with the absence of ascending branch. 


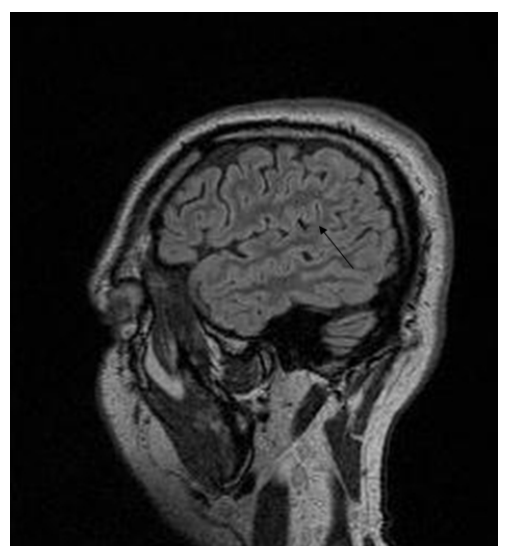

Figure 2. 3D FLAIR-parasagittal view of affected parietotemporal region; posterior branch is interrupted and terminates at the level of the preoccipital notch.

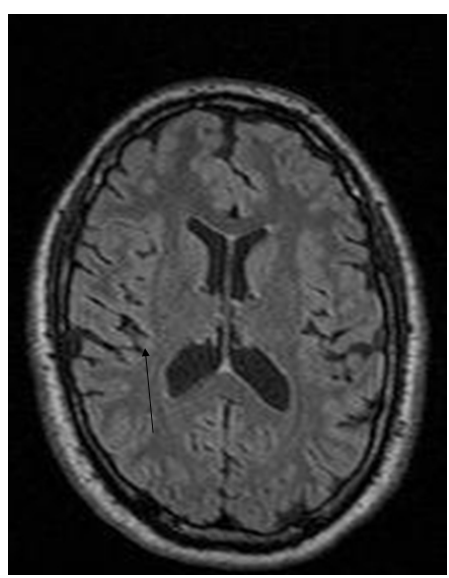

Figure 3. 3D FLAIR-axial view of affected parietotemporal region; the cause of interruption is polymicrogyria in the parietotemporal region.

of the genitalia. Follow up studies of the patients with clinical syndromes in which the hormonal environment of the fetus has been atypical, have provided data on possible effects of prenatal sex steroids on sexual orientation and gender role stereotypes [12-14].

Behaviorists state that an infant's mind is a blank slate upon which social factors and conditioning act to produce all aspects of personality, including gender [7]. This belief takes the form of an axiom in their works and that is a basic assumption not based in evidence but upon which they derive results.

Sexual brain differentiation through embryonic development deviates from the sexual differentiation of the rest of the body [5] and that is why we state that neuroanatomy plays a critical role in determining gender identity and can help us in identifying underlying mechanisms of transsexualism.

The human brain differentiates early in development both structurally and functionally in a sexually dimorphic way [15] which leads to the fact that transsexualism is a sexual differentiation disorder of the sex dimorphic brain [13]. There are a number of different studies that examined brain structure and their correlate to this gender identity disorder [16]. Some of them are postmortem studies, which revieled anatomical supstrates which are sexually dimorphic like bed nucleus of stria terminalis [5], INAH3 [17] and number of neurons [18]. There were also data presented on brain assymetry and cortical cytoarchitectonics areas which were included in Fmri examination in transsexuals.

Resent advances in imaging have shown that polymicrogyria have many apperiances on MRI imaging which leads us to conclusion that is apperently more various malformation than described before. It is often associated with specific syndromes [19-22]. It is very common seen in epilepsy. Our patient did not give us data on epilepsy or any other clinical syndrome that can ocure in transsexualism. Development of cerebral cortex is so complex that it is no suprising that disruptions of the processes of late cortical migration and cortical organisation at different stages might result in slightly different malformations and different clinical implications and manifestations, even within transsexualism. The apperiance can be shown like small and very delicate gyri or thick and irregulary, bumpy $[4,23]$. The cortex can also have an apperiance of palisade. There are number of factors that can tribute to this condition, but we take stage of maturity or myelination of the brain like one of the most affective because the degree of myelination affects the apperance. In unmyelinated regions the inner surface of the polymicrogyric cortex looks thin and pretty bumpy, while in myleinated areas it looks thicker and smoother. Polymicrogyria is a malformation with many faces so it is of major significance to have that in mind when examing the MRI scans.

All mentioned genetic, hormonal and psychosocial factors cannot influence independetly, but yes predominantly by each in specific conditions. United influence can tribute to the development of transsexualism.

The exact underlying mechanisms and determinants remain to be established in future work, where interplay between genetic determination, hormonal exposure, and environment is very likely.

\section{Conclusion}

This is a first case, to our knowladge, which dealt with polymicrogyria, and which was revealed in a transsexual patient. There is no other brain abnormality or disfunction obtained in this patient. Although there is no evidence of the polymicrogyria to influence the appearance of transsexuality, further investigations ought to lead to the detection of possible brain abnormalities of any kind of MRI scans of the transsexuals. 


\section{REFERENCES}

[1] P. T. Cohen-Kettenis and L. J. Gooren, “Transsexualism, a Review of Etiology, Diagnosis and Treatment,” Journal of Psychosomatic Research, Vol. 46, No. 4, 1999, pp. 315-333. http://dx.doi.org/10.1016/S0022-3999(98)00085-3

[2] A. J. Barkovich, "Current Concepts of Polymicrogyria," Neuroradiology, Vol. 52, No. 6, 2010, pp. 479-487. http://dx.doi.org/10.1007/s00234-009-0644-2

[3] R. J. Leventer, A. Jansen, D. T. Pilz, N. Stoodley, C. Marini, F. Dubeau, et al., "Clinical and Imaging Heterogeneity of Polymicrogyria: A Study of 328 Patients,” Brain, Vol. 133, No. 5, 2010, 1415-1427. http://dx.doi.org/10.1093/brain/awq078

[4] A. J. Barkovich, P. Gressens and P. Evrard, "Formation, Maturation and Disorders of Brain Neocortex," AJNR American Journal of Neuroradiology, Vol. 13, 1992, pp. 423-446.

[5] J. N. Zhou, M. A. Hofman, L. J. Gooren and D. F. Swaab, "A Sex Difference in the Human Brain and Its Relation to Transsexuality,” Nature, Vol. 378, No. 6552, 1995, pp. 68-70. http://dx.doi.org/10.1038/378068a0

[6] S. M. Corsello, V. Di Donna and P. Senes, et al., "Biological Aspects of Gender Disorders," Minerva Endocrinologica, Vol. 36, No. 4, 2011, pp. 325-339.

[7] A. M. Bao and D. F. Swaab, "Sex Differences in the Brain, Behaviour, and Neuropsychiatric Disorders," Neuroscientist, Vol. 16, No. 5, 2010, pp. 550-565. http://dx.doi.org/10.1177/1073858410377005

[8] C. Kraus, “Am I My Brain or My Genitals? A NatureCulture Controversy in the Hermaphrodite Debate from the Mid-1960s to the Late 1990s," Gesnerus, Vol. 68, No. 1, 2011, pp. 80-106.

[9] A. A. Lawrence, "A Critique of the Brain-Sex Theory of Transsexualism,” Transsexual Women's Resources, 2007.

[10] I. Savic, A. Garcia-Falgueras and D. F. Swaab, "Sexual Differentiation of the Human Brain in Relation to Gender IDENTITY and Sexual Orientation," Progress in Brain Research, Vol. 186, 2010, pp. 41-62. http://dx.doi.org/10.1016/B978-0-444-53630-3.00004-X

[11] D. F. Swaab, L. J. Gooren and M. A. Hofman, “Gender and Sexual Orientation in Relation to Hypothalamic Structures," Hormone Research, Vol. 38, No. 2, 1992, pp. 51-61. http://dx.doi.org/10.1159/000182597

[12] D. F. Swaab, “Sexual Differentiation of the Human Brain: Relevance for Gender Identity, Transsexualism and Sexual Orientation,” Gynecological Endocrinology, Vol. 19, No. 6, 2004, pp. 301-312. http://dx.doi.org/10.1080/09513590400018231
[13] L. Gooren, "The Biology of Human Psychosexual Differentiation,” Hormones and Behavior, Vol. 50, No. 4, 2006, pp. 589-601 http://dx.doi.org/10.1016/j.yhbeh.2006.06.011

[14] A. M. Bao and D. F. Swaab, "Sexual Differentiation of the Human Brain: Relation to Gender Identity, Sexual Orientation and Neuropsychiatric Disorders," Frontiers in Neuroendocrinology, Vol. 32, No. 2, 2011, pp. 214-226. http://dx.doi.org/10.1016/j.yfrne.2011.02.007

[15] D. F. Swaab, "Sexual Differentiation of the Brain and Behaviour,” Best Practice \& Research Clinical Endocrinology \& Metabolism, Vol. 21, No. 3, 2007, pp. 431-444. http://dx.doi.org/10.1016/j.beem.2007.04.003

[16] W. C. Chung, G. J. De Vries and D. F. Swaab, "Sexual Differentiation of the Bed Nucleus of the Stria Terminalis in Humans May Extend into Adulthood," Neuroradiology, Vol. 22, No. 3, 2002, pp. 1027-1033.

[17] A. Garcia-Falgueras and D. F. Swaab, “A Sex Difference in the Hypothalamic Uncinate Nucleus: Relationship to Gender Identity,” Brain, Vol. 131, No. 12, 2008, pp. 31323146. http://dx.doi.org/10.1093/brain/awn276

[18] F. P. M. Kruijver, J. N. Zhou, C. W. Pool, M. A. Hofman, L. J. Gooren and D. F. Swaab, "Male-to-Female Transsexuals Have Female Neuron Numbers in a Limbic Nucleus,” The Journal of Clinical Endocrinology \& Metabolism, Vol. 85, No. 5, 2000, p. 2034. http://dx.doi.org/10.1210/jc.85.5.2034

[19] M. Rijpkema, D. Everaerd, C. van der Pol, B. Franke, I. Tendolkar and G. Fernández, "Normal Sexual Dimorphism in the Human Basal Ganglia," Human Brain Mapping, Vol. 33, No. 5, 2011, pp. 1346-1252. http://dx.doi.org/10.1002/hbm.21283

[20] J. Brabec, J. Krásený and P. Petrovický, "Volumetry of Striatum and Pallidum in Man-Anatomy, Cytoarchitecture, Connections, MRI and Aging," Sbornik Lekaisky, Vol. 104, No. 1, 2003, pp. 13-65.

[21] Y. Miyahira, J. Yu, K. Hiramatsu, Y. Shimazaki and Y. Takeda, "Brain Volumetric MRI Study in Healthy Elderly Persons Using Statistical Parametric Mapping,” Seishin Shinkeigaku Zasshi, Vol. 106, No. 2, 2004, pp. 138-151.

[22] L. G. Almeida Montes, J. Ricardo-Garcell, L. B. Barajas De La Torre, et al., "Clinical Correlations of Grey Matter Reductions in the Caudate Nucleus of Adults with Attention Deficit Hyperactivity Disorder," Journal of Psychiatry and Neuroscience, Vol. 35, No. 4, 2010, pp. 238-246. http://dx.doi.org/10.1503/jpn.090099

[23] A. J. Barkovich, "MRI Analysis of Sulcation Morphology in Polymicrogyria,” Epilepsia, Vol. 51, No. 1, 2010, pp. 17-22. http://dx.doi.org/10.1111/j.1528-1167.2009.02436.x 